\title{
BIODESARROLLO Y DIÁLOGO INTERRELIGIOSO ¿GLAVES PARA LA SUPERAGIÓN DE UN POSIBLE ENFRENTAMIENTO ENTRE LAS CULTURAS DE LA HUMANIDAD? 1
}

(Recepción: Abril 9 de 2013- Aceptación: Mayo 27 de 2013)

José de Jesús Herrera Ospina*

\section{Resumen}

La urgente necesidad de pensar el desarrollo a escala humana, a partir del concepto Bios (vida), considerándolo como el principal valor y el punto de referencia de toda posibilidad de creación y recreación del ethos, valga decir, del entorno, lleva también a vincular el tema de la religión en el campo del llamado ecumenismo, que no es más que la reflexión dialogada de las religiones que busca alternativas de consenso mundial a partir de una ética común universal.

Según los planteamientos del politólogo y sociólogo norteamericano Samuel Huntington, de los teólogos Hans Küng (Alemania) y Alberto Ramírez (Colombia), me atrevo a presentar un breve estado de la cuestión que si bien, no trata de dar fórmulas mágicas de resolución de conflictos si espera ser una herramienta de diálogo y de desarrollo a escala humana que permita entender la vida en este complejo mundo.

\section{Palabras clave}

Diálogo, Religión, Desarrollo Humano, Biodesarrollo

\section{BIODEVELOPMENT AND DIALOGUE: KEY TO OUEREOME A POSSIBLE GONFRONTATION BETWEEN CULTURES OF HUMANITYP}

\section{Alustract}

The urgent necessity to think the development in a human scale, from the concept ofBios(life) as departure point, considering it as the most important value and the referent axis for all possibilities of creation and re-creation of our ethos, that is, our environment, all this guides us to take into account Religions in the field of ecumenism, searching for different forms of a world consensus based on common universal ethics.

According to the statements of the expert in politics and sociologist Samuel Huntington and the theologians Hans Kung (Germany) and Alberto Ramirez (Colombia), I dare to present some points of view that are not magic formulas to solve all problems, but are means of dialogue for increasing a view of development in a human scale that let us understand our lives in a complex world than surround us.

\section{Keywords}

Dialogue, Religion, Human Development, Bio-Development.

\footnotetext{
1 El presente artículo de reflexión fue expuesto en el VI Congreso Latinoamericano sobre Ciencia y Religión. Perspectivas LatinoamericanasDiálogo Global celebrado en la Pontificia Universidad Católica de Río de Janeiro los días 2 y 4 de Octubre de 2012. El evento fue convocado por el Instituto lam Ramsey, Centro para la investigación sobre Ciencia y Religión de la Universidad de Oxford (Inglaterra).

* Docente investigador de la Facultad de Ciencias Básicas, Sociales y Humanas del Politécnico Colombiano Jaime Isaza Cadavid y Catedrático del Instituto de Filosofía de la Universidad de Antioquia. (Medellín-Colombia). Nacionalidad: colombiano. Doctor en Filosofía por la Universidad Pontificia Bolivariana. jjherrerao@elpoli.edu.co; joseherrera99@hotmail.com
} 


\section{Introducción}

Samuel Huntington (2001) en su famoso texto: The crash of civilizations expresaba de manera preocupante que las guerras y conflictos del siglo XXI serían choques culturales, jalonados principalmente por la religión. Si se observa lo ocurrido en la primera década del siglo XXI con el enfrentamiento exacerbado de los Estados Unidos y países aliados contra algunos países del Medio Oriente, se comprobaría tal tesis: el presidente norteamericano George W. Bush -quien incluso se consideró iluminado por Dios- mandó invadir a Irak. Ni qué decir de la búsqueda del terrorista islámico más famoso que haya existido hasta hoy: Osama Bin Laden, los atentados de Osama se justificaron en nombre de la Guerra Santa y la persecución de Bush contra Osama en nombre de la seguridad democrática mundial en contra del terrorismo mundial. En ambos casos, la afectada fue la tierra y sus habitantes, en última instancia, la vida fue maltratada en todos los aspectos: bombas y material de guerra arrojadas a hospitales y escuelas, detonación de armas de destrucción masiva, civiles muertos, ciudades destruidas y contaminación del medio ambiente, entre otros.

Los teólogos Hans Küng en Alemania y Alberto Ramírez en Colombia han propugnado desde la visión de la teología humanista, un nuevo modo de ver el desarrollo a escala humana, desde la mirada ética y el diálogo interreligioso. Hans Küng ha llamado la atención sobre el hecho que no habrá paz en el mundo, sin el diálogo serio de las distintas perspectivas religiosas de la humanidad, y sólo el paradigma ético llegará a cambiar el estado de la cuestión social y cultural, que en la actualidad es realmente degradante. Las culturas están íntimamente ligadas al proceso de eticidad de quienes la conforman. La ética pasa a ser la única tabla de salvación del género humano en el siglo XXI. De ahí la frase "El siglo XXI será ético o no será" que han enarbolado pensadores laicos como Gilles Lipovestky, en particular su obra: El crepúsculo del deber: la nueva ética indolora de los nuevos tiempos democráticos. Por su parte, Alberto Ramírez ha defendido la tesis que sólo desde un diálogo interreligioso, ecuménico, pluralista y profundamente humano es posible hacer de la sociedad en que se encuentra el hombre un lugar digno para la vida. Al menos, así lo impartió en su Cátedra de Diálogo entre las Grandes Religiones de la Humanidad en la Maestría en Estudios Bíblicos con énfasis en Ecumenismo de la Universidad de Antioquia (1999) y es lo que ha realizado en sus actividades como docente y sacerdote de la Arquidiócesis de Medellín (Colombia).

El Biodesarrollo, entiéndase el desarrollo de la vida en general y, por ende, la humana está, pues, íntimamente ligado a las concepciones sociales, religiosas y culturales. Muy probablemente así siempre ha sido, es y será. Simplemente, la historia ha mostrado que para no repetir crasos errores es necesario conocerla y reconocerla en el valor del otro en la diferencia.

\section{El choque de las civilizaciones y la nueva cultura emergente}

Samuel Huntington (2001) fue claro en afirmar que el siglo XXI sería el siglo de las guerras de la cultura, enraizadas principalmente en las cuestiones étnicas y religiosas:

En este nuevo mundo, los conflictos más generalizados, importantes y peligrosos no serán los que se produzcan entre clases sociales, ricos y pobres u otros grupos definidos por criterios económicos, sino los que afecten a pueblos pertenecientes 
a diferentes entidades culturales. Dentro de las civilizaciones tendrán lugar guerras tribales y conflictos étnicos. (p. 17)

En su vasto análisis sociológico ofrece un panorama poco alentador del futuro de la humanidad, llevado de la mano de la tesis de Francis Fukuyama del <Fin de la Historia $>$. No obstante, cabe preguntarse si estos conflictos no son los que siempre han acompañado el destino histórico de todos los pueblos y naciones durante el desarrollo de la humanidad.

Para efectos de delimitar el análisis de estos fenómenos, sólo se tendrán en cuenta dos tesis de Huntington, para responder a ellas desde las tesis de los mencionados teólogos $\mathrm{H}$. Küng y $\mathrm{A}$. Ramírez.

\subsection{La tesis del}

resurgimiento de lo religioso como fuente de conflicto o su posible interpretación como fuente de unidad

El análisis sociológico de Huntington está orientado a la tesis del resurgimiento de lo religioso en Occidente y, en general, en el mundo globalizado. Tesis por lo demás nada nueva ya que $\mathrm{H}$. Cox en su famoso libro La ciudad secular vislumbraba un nuevo comienzo para las religiones en general y en particular del cristianismo, al afirmar que la sociedad científica y tecnológica o lo que se ha denominado en la actualidad como $<$ tecnociencia $>$ (se ha hablado también de <tecnópolis $>$ ) pone al cristiano o al hombre religioso en general, ante un nuevo fenómeno experiencial de la fe <la secularización $>$, como un fenómeno que lo reta a responder y a vivir su camino religioso comprendiendo los nuevos contextos culturales en los que está inmerso.
Pero es menester indagar sobre algunos aspectos que recalca Huntington (2001):

La causa más obvia, destacada y profunda del resurgimiento religioso mundial es precisamente lo que supuestamente había de provocar la muerte de la religión: los procesos de modernización social, económica y cultural que se difundieron por todo el mundo en la segunda mitad del siglo XX. Fuentes de identidad y sistemas de autoridad existentes desde mucho tiempo atrás se rompen. Los campesinos emigran del campo a la ciudad, se alejan de sus raíces y realizan trabajos nuevos o no trabajan. Interaccionan con gran número de extraños y se ven expuestos a nuevas series de relaciones. Necesitan nuevas fuentes de identidad, nuevas formas de agrupación estable y nuevos conjuntos de preceptos morales que les proporcionen un sentimiento de sentido y finalidad. La religión, sea moderada o fundamentalista, satisface tales necesidades. (p. 91)

La noción de identidad hace que el hombre religioso cree un imaginario de vida acorde a sus creencias. El mundo religioso es, en definitiva, una apuesta por la identidad. Identidad del hombre con Dios, con los demás, consigo mismo. Las religiones son procesos de identificación cultural y también de desidentificación con miras a alcanzar otras formas de identidad. Cada día se está identificando y des-identificando el hombre en sus contextos en los que vive. El hecho del multiculturalismo hace posible esta situación (hoy se habla más de reconocimiento de las etnias, no obstante, el término no es nada nuevo)

Según Macionis y Plummer (1999):

El multiculturalismo es una corriente de pensamiento orientada hacia el reconocimiento de la diversidad cultural (tanto 
en el presente como en el pasado) y hacia la igualdad de todas las tradiciones culturales. Esta corriente es una clara desviación de aquel modo de pensar o interpretar la historia de la humanidad desde una única perspectiva occidental. (p. 124)

Es menester, aclarar el concepto de $<$ igualdad > en esta definición. No se debe entender igual como uniformidad, sino como unidad en la diversidad. El ecumenismo o mejor dicho, el macro ecumenismo o diálogo interreligioso, bien lo define:

Arboleda (2003):

En forma resumida podemos decir que el diálogo interreligioso no se orienta a unirse como el diálogo ecuménico. Su fin es conocernos más, respetarnos y colaborar para construir un mundo mejor. Juntos podemos luchar por los verdaderos valores y por la justicia, la paz, la superación de la pobreza y otros problemas, logrando un diálogo de civilizaciones. (p.17)

De lo que se trata es de reconocer el fenómeno del resurgimiento de lo religioso como un asunto que en vez de llevar al conflicto - que bien lo pudiera hacer y de hecho, lo hace en muchas ocasiones- pueda llevar a la búsqueda de unidad, entendiéndola como un proceso de integración humana y no de integrismo o fanatismo. Todo enmarcado en el concepto de cambio cultural:

Macionis y Plummer (1999) dicen:

Ya Heráclito decía que la esencia de las cosas es un continuo cambio o devenir. No sabemos si la humanidad sobrevivirá los próximos millones de años; al fin y al cabo, otras especies ya han desaparecido de la faz de la tierra. Pero de lo que sí podemos estar seguros es que, mientras haya sociedad, habrá cultura. (p.116)

Uno de los fenómenos del resurgimiento de lo religioso en la actualidad está representado en la nueva forma de < religiosidad > , o mejor llamada $<$ espiritualidad $>$ que se denomina $<$ Nueva Era $>0<$ New Age $>$. Sin ánimo de profundizar en la cuestión, sólo se quiere apuntalar una característica de la Nueva Era, que redunda en la tesis del reconocimiento de la otredad y la diferencia: el holismo.

¿Qué se puede entender por holismo? El término no es nuevo, proviene del griego holos, que significa <todo>. La norteamericana Marylin Ferguson tiene, a propósito en su obra The Acquarian Conspiracy, una aproximación interesante a este fenómeno.

\section{Afirma Ferguson (1994):}

Vivimos de acuerdo con lo que sabemos. Si creemos que el universo y nosotros mismos somos algo mecánico, viviremos de forma mecánica. Por el contrario, si sabemos que formamos parte de un universo abierto, y que nuestra mente es una matriz de realidad, viviremos la vida más creativamente y con mayor energía. Si nos imaginamos como seres aislados, flotando en un océano de indiferencia, nos comportaremos en la vida de forma diferente a como lo haríamos de sabernos en un universo total indivisible. Si creemos que el mundo es fijo, nos opondremos a todo cambio; si sabemos que el mundo es fluido, seremos cooperadores del cambio. (p.152)

Se rescata la parte final del texto para efectos del reconocimiento de la unidad como fuente de convivencia. $<$ Cooperadores de cambio>, nótese, que se habla de cooperador no de operador. El cooperador, trabaja junto con el otro, el operador no necesariamente lo hace. Es la conspiración de la nueva humanidad contra los dominios del totalitarismo y de la tozudez de la humanidad que sólo ve en el conflicto cerrado, la única posibilidad de cambio. En otras palabras, 
la paz de la humanidad se encuentra en el reconocimiento del otro por su valor de humanidad, característica que hace a todos valiosos y colaboradores (constructores) de una nueva sociedad emergente, un nuevo Biodesarrollo, una nueva religiosidad y una nueva espiritualidad.

\subsection{La tesis del universalismo occidental como forma de choque de las civilizaciones}

\begin{abstract}
Afirma Huntington (2001):
El universalismo occidental es peligroso porque se basa en un espejismo, el de la centralidad de Occidente en la historia universal. Es peligroso para el mundo porque podría conducir a una gran guerra entre Estados centrales de diferentes civilizaciones, y es peligroso para Occidente porque podría llevar a la derrota de Occidente. Con el hundimiento de la Unión Soviética, los occidentales ven su civilización en una posición de dominio sin parangón, mientras que, al mismo tiempo, sociedades más débiles, asiáticas y musulmanas, entre otras, están empezando a cobrar fuerza. (pp. 305-306)
\end{abstract}

Esta tesis del universalismo occidental proviene de la misma cuna de la cultura occidental: Grecia. En su mayor esplendor, con Alejandro Magno, la Magna Grecia se consideró a sí misma la única potencia del mundo conocido. El imperio Griego se extendió hasta las regiones más distantes: India hacia el Oriente, Hispania al Occidente. Posteriormente Roma, como Urbs Condita también fue garante de esta expansión universal. El imperio romano llegó hasta los más recónditos lugares. El cristianismo radicado en Roma, es decir, oficializado como religión del imperio por Teodosio en el 392 se extendió por toda Europa y posteriormente por todo el mundo conocido. Fue con el descubrimiento y conquista de América (1492 y años siguientes) que el catolicismo, por una parte, se globaliza y se convierte en la cultura universal dominante y por otra, el cristianismo reformado conquista y se afianza en la parte Norte de América. En fin, la tesis del universalismo occidental. No es menester entrar en discusión si la tesis del universalismo es sólo occidental, porque es bien conocida la tesis del universalismo oriental, particularmente, la expansión del Islam en Occidente desde los mismos orígenes de la religión musulmana.

Son muchos los estudios que al respecto se han hecho sobre la tesis del universalismo o expansionismo occidental y sobre sus pro y contra. Una buena reflexión y crítica de la sociedad occidental, desde el punto de vista de la concepción filosófica se encuentra en la obra de Oswald Spengler, <La decadencia de Occidente>. En su Introducción dice a propósito: Spengler (1966):

La decadencia de Occidente, que por lo pronto, no es sino un fenómeno limitado en lugar y tiempo, como lo es su correspondiente la decadencia de la "Antigüedad", resulta, pues, un tema filosófico que, considerado en todo su peso, implica todos los grandes problemas de la realidad. Si queremos saber en qué forma se está verificando la extinción de la cultura occidental, habrá que averiguar primero qué sea cultura, en qué relación se halle la cultura con la historia visible, con la vida, con el alma, con la naturaleza, con el espíritu; en qué formas se manifieste, y hasta qué punto sean esas formas - pueblos, idiomas y épocas, batallas e ideas, Estados y dioses, artes y obras, ciencias, derechos, organizaciones económicas y concepciones del universo, grandes hombres y grandes acontecimientos símbolos $y$, por lo tanto, cuál deba ser su interpretación legitima. (pp. 16-17)

Se sustrae de este párrafo la idea de extinción de la cultura que para 
Spengler tiene, en cierto sentido, un halo de pesimismo. Pero es de anotar que el pesimismo spengleriano con respecto al futuro de la sociedad occidental, hunde sus raíces en la antagónica visión de optimismo sobre la civilización occidental, heredada del pensamiento hegeliano. La tesis, heredada de la llustración Francesa, de progreso absoluto de la razón, se convirtió también en la paradoja del real progreso y evolución de la cultura occidental que tiene -en los campos de concentración de Auschwitz, y en el Apartheid de Suráfrica - la manifestación más compleja del endiosamiento de la razón y la tesis radical del universalismo occidental que produce un choque de civilizaciones, valga decir, un choque fatal entre las culturas de la humanidad. Enarboladas las ideas de Progreso, Razón y Evolución, desde una interpretación mal elaborada, se han dado los mayores atropellos a la dignidad humana y al planeta en general.

En el mismo sentido se ha expresado un digno representante de la Escuela de Frankfurt, el alemán Herbert Marcuse, quien en su obra El hombre unidimensional, afirma:

\section{Expresa Marcuse (1969):}

Nada permite suponer que sea un buen fin. Las capacidades económicas y técnicas de las sociedades establecidas son suficientemente grandes para permitir ajustes y concesiones a los parias, y las fuerzas armadas están suficientemente entrenadas y equipadas para ocuparse de las situaciones de emergencia. Sin embargo, el espectro está ahí otra vez, dentro y fuera de las sociedades más avanzadas. El fácil paralelismo histórico con los bárbaros amenazando el imperio de la civilización crea un prejuicio sobre el tema; el segundo período de barbarie puede ser el imperio continuado de la misma civilización. Pero existe la posibilidad de que, en este período, los extremos históricos se encuentren otra vez: la conciencia más avanzada de la humanidad y la fuerza más explotada. No es más que una posibilidad. La teoría crítica de la sociedad no posee conceptos que puedan tender un puente sobre el abismo entre el presente y su futuro: sin sostener ninguna promesa, ni tener ningún éxito, sigue siendo negativa. Así, quiere permanecer leal a aquellos que, sin esperanza, han dado y dan su vida al Gran Rechazo. En los comienzos de la era fascista, Walter Benjamin escribió: Nurum der Hoffnunglosenwillenistuns die HoffnunggegebenSólo gracias a aquellos sin esperanza nos es dada la esperanza. (p. 286)

Independiente de la ideología que se pueda encontrar en el citado texto y del propósito neo-marxista de establecer una crítica social a la sociedad occidental capitalista con el fin de establecer nuevas condiciones sociales, económicas y políticas en Occidente, es necesario rescatar varios conceptos inmersos en la crítica del pensamiento marcusiano:

- La crítica a una <sociedad cerrada> que ha construido el capitalismo exacerbado y que no permite pensar en un Biodesarrollo donde las culturas distintas a la cultura norteamericana y/o anglosajona tengan participación efectiva y real para los destinos de la humanidad. Verbigratia, el asunto actual de la internacionalización de la Amazonía, debe ser pensada desde una perspectiva amplia (aquí se hace alusión a aspectos como la mirada interdisciplinaria: la ecología, las humanidades y las ciencias, entre otras.) y no sólo la visión economicista como se expresan hoy grandes transnacionales o multinacionales.

- La crítica a una <sociedad de la opulencia > representada en el poder económico y político de los países que controlan la economía mundial, que permita pensar en aspectos de 
Biodesarrollo locales, regionales, nacionales, sin llegar, lógicamente al extremo de la localización fundamentalista y también cerrada que no dialoga con los otros.

- La crítica a determinadas < políticas de represión global> que heredadas de un pensamiento marcadamente neo imperialista, han hecho tanto daño a la humanidad en general, a las culturas locales, al planeta con la contaminación ambiental y causado un sinnúmero de problemas sociales, políticos, económicos y culturales.

\section{El diálogo interreligioso y la construcción de un nuevo paradigma ético universal}

En este segundo momento de la reflexión sobre el Biodesarrollo, se propone hacer un acercamiento general a la tesis del diálogo interreligioso en relación con la construcción consensuada de un paradigma ético universal. Para ello, la reflexión tendrá dos autores de cabecera, los teólogos Hans Küng y Alberto Ramírez. Ambos desarrollan la tesis del ecumenismo, o mejor decirlo, del macro ecumenismo.

\subsection{Hans küng y su fórmula: no habrá paz entre las religiones $\sin . .$.}

La muy conocida fórmula küngiana No hay paz entre las naciones sin (...) se ha convertido en un eslogan muy importante para la reflexión en torno a la búsqueda de las condiciones mínimas para alcanzar la paz en el mundo. Esta búsqueda de la paz mundial tiene como base los valores fundamentales de la ética y la construcción conjunta de un imaginario de tolerancia y respeto entre las distintas culturas y particularmente entre las religiones. Para ello Küng (1992. p.85) afirma que:
No hay paz entre las naciones sin un mínimo de componentes éticos fundamentales: La reflexión se centra en los componentes de la ética desde los valores inmersos en ella. Dos caminos que llevan a esto son: la voluntad para resolver los conflictos sociales y el respeto por el orden.

\section{Afirma Küng (1992):}

En nuestros días, podemos hablar ya de una amplia coincidencia: sin un consenso básico mínimo sobre determinados valores, normas y actitudes, resulta imposible una convivencia humana digna, tanto en pequeñas como en grandes sociedades (...). (p. 46)

La sociedad debe ser ética por su naturaleza humana y social, más concretamente, por su naturaleza política. El hecho de ser ciudadanos, es decir, seres políticos (habitantes de la polis) debe llevar a la consideración que en lo más profundo del ser humano habita el valor de su dignidad humana, los principios éticos y también políticos. La convivencia política y social depende de los valores humanos integrados a ella.

- No hay paz entre las naciones sin la búsqueda de espacios de tolerancia y respeto entre las culturas, especialmente de las religiones: Uno de los aspectos importantes a valorar en el mundo actual es $<e l$ multiculturalismo $>$ que se enfrenta comúnmente contra el Ilamado <etnocentrismo>. Es necesario destacar el concepto de multiculturalismo que se enunció al comienzo de este artículo con los anglosajones Macionis y Plummer. En éste se ha de entender la igualdad no como uniformidad de las culturas sino como el reconocimiento del derecho fundamental consignado en la <Declaración de los Derechos Humanos $>$, donde el principio fundamental estriba en que todos los hombres nacen iguales en dignidad 
y respeto. Si esto es así, las culturas que están compuestas por seres humanos, son iguales en dignidad y respeto. Dentro de las culturas un espacio importante de reflexión son las religiones. Por ello...

- No hay paz entre las naciones sin diálogo entre las religiones: Con esta frase terminan las obras que conforman la trilogía sobre las tres grandes religiones monoteístas: judaísmo, cristianismo e islam. Imperativo de gran importancia tanto por el pasado, presente y porvenir de la humanidad. Se hablaría, incluso, ya no sólo de las tres grandes religiones monoteístas sino de todas las religiones del mundo, o sea, además de éstas, el budismo, el sintoísmo, el hinduismo y las religiones afroamericanas, entre otras. Se debe pasar del paradigma de Huntington (el choque de las civilizaciones) al paradigma de Küng (el diálogo entre las civilizaciones). ¿Cómo? A partir de una nueva conciencia ética, basada en el respeto por el otro, por sus diferencias, por sus creencias, por su intimidad y por su conciencia. Las religiones siempre han sido un motor de desarrollo de la historia, por ende, para que el desarrollo sea como lo afirma Max Neef, un verdadero $<$ desarrollo a escala humana $>$, se necesitan los valores éticos para garantizar el desarrollo real del hombre en sociedad.

\section{Küng (1992) asevera que:}

Las religiones pueden (...) actuar como instrumento de liberación, de orientación al futuro y de fraternidad, y lo han hecho también con frecuencia; pueden extender la confianza en la vida, la magnanimidad, la tolerancia, la solidaridad, la creatividad, y el compromiso social; pueden fomentar la renovación espiritual, las reformas sociales y la paz mundial. (p.68)

\subsection{Alberto Ramírez y <la teología latinoamericana abierta al diálogo con...>}

En este segundo momento de la reflexión sobre la propuesta de diálogo interreligioso, es menester, presentar desde la perspectiva latinoamericana, el pensamiento de un teólogo, que comparte muchas ideas y propuestas de teólogos tan importantes como Juan Bautista Metz, Hans Küng, Leonardo Boff y Gustavo Gutiérrez, entre otros, el sacerdote Alberto Ramírez, doctor en teología de la Universidad Católica de Lovaina. Se tendrán en cuenta, principalmente, dos artículos publicados en la revista Cuestiones Teológicas de la Universidad Pontificia Bolivariana en los años 1999 y 2000 , respectivamente. El primero titula El reto actual de la apertura toca también a la Iglesia y a la teología y Consideraciones teológicas acerca del misterio de Dios. Se dejará de lado una gran cantidad de producción intelectual por motivos de extensión de este artículo, no obstante, se relacionarán al inicio y al final dos textos también de suma importancia para efectos de comprender esta temática, al menos en su generalidad.

El punto de partida de la reflexión se encuentra en lo que significó y significa actualmente el Concilio Vaticano I/. El famoso <aggiornamento > propuesto por el Papa Juan XXIII y continuado por los padres conciliares y su sucesor Pablo VI, se convierte en un asunto fundamental para la nueva teología mundial y en particular para Latinoamérica. En otro artículo más reciente, el cual sólo se mencionará de modo sucinto, intitulado: $<A$ los 40 años de la inauguración del Concilio Vaticano II. 11 de octubre de 2002 > afirma Ramírez (2003) que:

Dentro de los propósitos originales del Concilio hay que señalar el interés por responder, desde la Iglesia, a los retos del mundo actual, el mundo moderno 
contemporáneo, con una actitud de diálogo en todos los sentidos. La actitud del Papa Juan XXIII inspirará el espíritu que animó al Concilio en este sentido durante todas las sesiones, espíritu de diálogo en relación con los hermanos cristianos no católicos; espíritu de diálogo en relación con las religiones no cristianas; espíritu de diálogo en relación con el mundo moderno. (p.35).

Se observa de inmediato el propósito conciliar aún vigente: Una Iglesia adecuada al tiempo que le corresponde vivir, interesada por los problemas del hombre, de la sociedad y de la cultura. Con perspectivas de diálogo en todos los niveles: social, económico, religioso, político y científico, entre otros. Se rescata, particularmente, el nivel religioso, donde lo ecuménico y lo macro ecuménico se constituyen en una de las prioridades fundamentales del <aggiornamento $>$.

Precisamente, el primer artículo menciona los retos que plantea el mundo moderno a la teología del futuro en el contexto latinoamericano:

- La apertura en relación con el cuestionamiento de una ideología sin alternativas

- La apertura en relación con la comprensión de la opción por los pobres.

- La apertura en relación con la necesidad de integrarnos cada vez más en el mundo universal, en un sentido religioso, eclesial y teológico

- Hacia una teología en la cual se da razón de una praxis pastoral de la liberación, en el plano personal.

En estos retos se condensan muchos planteamientos del Concilio Vaticano II, en el sentido de la actualización de la Iglesia en el mundo.
Desde la perspectiva inicial, también se plantean asuntos relativos al propósito señalado: Pensar el desarrollo humano en clave ecuménica para un verdadero biodesarrollo en clave religiosa. Dos textos de Ramírez (1999) dan fe de esta preocupación:

I. La teología de una Iglesia profética latinoamericana debe abrirse a un futuro de apertura dialogal y global. No son simplemente razones prácticas las que lo exigen, como por ejemplo el hecho de evitar confrontaciones que podrían ser muy graves y convertirse en un gran obstáculo para la paz, a causa del crecimiento impresionante de alternativas religiosas distintas a las que hemos ofrecido las grandes iglesias, sobre todo el catolicismo. ¿No nos vamos encaminando tal vez hacia situaciones de guerra religiosa? Pero la razón de ser de una nueva actitud de apertura es mucho más profunda: nos encaminamos hacia un futuro en el cual debemos tener una conciencia mucho más clara de que somos una sola humanidad y de que, también en cuanto Iglesia, tenemos que tener una conciencia universal. (p. 136).

II. Una de las características de este mundo de la modernidad actual y futura es el hecho del pluralismo cultural. El diálogo que ahora se nos impone no es simplemente un diálogo con una cultura única, un poco del estilo de lo que se ha venido imponiendo por el llamado fenómeno de la globalización, o, como otros han dicho, por el fenómeno de la dominación universal de los corazones por la informática. Se trata ahora de un diálogo mucho más complejo y que exige una apertura mayor. Para el cristianismo y para la Iglesia católica, en concreto, un diálogo también con un mundo 
cada vez más secular. Las primeras motivaciones que se dieron acerca de la oportunidad de emprender una teología de la liberación cuestionaban expresamente la actitud de una teología moderna progresista, fundamentalmente europea, que trataba de tener en cuenta el hecho cultural de la secularización, como un elemento fundamental para realizar su tarea. Se decía entonces que este aspecto de la cultura del primer mundo no tenía nada que ver con nuestro mundo religioso latinoamericano. En cierto sentido se tenía razón al afirmarlo, porque habría sido algo así como tapar el sol con las manos querer desconocer la religiosidad popular de nuestro continente, tan generalizada. Se hizo bien, además, en valorar esta realidad de la religiosidad popular, al considerarla como el soporte simbólico de la sensibilidad religiosa de nuestras gentes, así como al señalar que la fe de los creyentes, por lo menos, entre nosotros, más que una actitud simplemente racional, tenía que ser reconocida como una actitud experiencial, en la que el lenguaje simbólico ocupa un lugar fundamental. (pp. 139-140).

Se rescatan de estos textos dos características que se han venido perfilando desde inicio: el reconocimiento de la multiculturalidad, el respeto por el otro como diferente y el reconocimiento de la dignidad humana en particular, del valor ético de la persona humana. El Biodesarrollo es una apuesta por el ser humano en contexto local y global. La vida humana en todas sus dimensiones (biológica, física, psíquica y espiritual) entra en relación recíproca con la vida en general. Las concepciones que se derivan de esta relación marcan la pauta para el desarrollo de la sociedad y del mundo, entendido como la totalidad del ser, en el sentido plenamente ontológico.
Del segundo artículo, se destaca un texto de importancia actual para el asunto en mención. Expresa Ramírez (2000):

Ahora bien, entre los agentes generadores de dinamismo utópico en la historia, la religión es, sin duda, uno de los más importantes, si no el más importante. Ella plantea ideales y tiene capacidad para sacar a las personas, a los grupos, a las culturas de la superficialidad. Creer en algo trascendente, en definitiva en Dios, significa, entre otras cosas, poder entrar en una dimensión de profundidad en la vida. No significa plantear las cosas en otro sentido, el hacer alguna consideración sobre la religión, desde el punto de vista del lenguaje, para designarla como la "poesía" de la vida: como lo que es la poesía en relación con el lenguaje en general, así es la religión en relación con la vida. Todas estas cosas se pueden plantear si lo utópico sigue desempeñando su papel en nuestras consideraciones, al hablar de religión. (p.112).

Este texto entra en plena sintonía con lo ya anotado al considerar el hecho religioso, o más claramente, la experiencia religiosa, como una forma de cultivo de la humanidad que propicia el desarrollo integral, en cuanto, como lo dice el teólogo Ramírez es una $<$ dimensión profunda de la vida $>$. Se repite de nuevo, la tesis que se ha querido mantener desde el inicio: sólo es posible entender el desarrollo humano desde la integralidad del hombre consigo mismo, con los otros y con Dios, entendiéndose todo ello desde el sentido humano de interioridad $\mathrm{y} / \mathrm{o}$ exterioridad profundas.

Para terminar, se hace alusión al reciente libro de A. Ramírez que lo realizó en coautoría con otros dos investigadores del Grupo de Investigación Iglesia, Teología y Cultura de la U.P.B - Medellín. El texto es: Hacia un futuro de grandes encuentros: Razones para fundamentar la esperanza 
Ramírez, Vargas y González (2011):

Se ha convertido en una verdadera urgencia, en un mundo en el que ha habido siempre tanta violencia, hablar de tolerancia. En relación con esta situación, tanto el cristianismo y la Iglesia como las religiones en general, tienen una gran misión por realizar: trabajar por la fraternidad entre los hombres y entre los pueblos. El cristianismo tiene una vocación especial en este sentido porque ella es, por naturaleza, una religión de la fraternidad, porque en ella se cultiva de manera radical la sensibilidad por lo humano y el sentido de la compasión. También en otras religiones se cultiva de manera ejemplar la actitud de la compasión, en particular en el budismo, pero en nuestra religión tiene un papel especial en este sentido el hecho de afirmar la paternidad universal de Dios, y por lo tanto, la fraternidad universal sin límites entre los hombres. La Iglesia, por su parte, es una comunidad que se siente llamada desde sus orígenes a derribar las barreras que dividen a los hombres, a los pueblos y a las culturas. (p.196).

\section{Conclusiones}

He aquí una puerta abierta a la reflexión madura y optimista del ser humano en relación con su cultura, con su entorno, consigo mismo. Un aporte al Bio desarrollo en clave humana, interreligiosa e intercultural. Posibilidades de $<$ encuentro $>$, a pesar de los posibles y reales <desencuentros> que como seres humanos que comparten un mundo de tanta complejidad se convierten en la razón de ser del vivir cotidiano. Diálogo permanente, en siempre viva y creciente construcción de la Ciencia y la religión, que como diría, otrora, un gran visionario de la cultura humana, Teilhard deChardin, (en carta dirigida al Conde Henri Bégouën, fechada el 9 de enero de 1955 y escrita en New York) reafirma una esperanza y una ilusión en el futuro de la humanidad.

Afirma de Chardin (1967):
(...) Su vida ha sido un largo testimonio a la verdad, y además una larga afirmación de fe en el valor fundamental del Hombre y del Mundo. Me parece que de esta fidelidad y de esta fe puede emerger para usted una inmensa confianza con respecto a lo que a todos nos espera al término de nuestra vida. La confianza (una confianza inagotable y total) en el gran empuje de "ser" que nos hizo y nos arrastra: esta actitud es la única que ciertamente no puede ni equivocarnos. iMaravillosa, irremplazable función la del Cristianismo, que desarrolla esta confianza hasta la posibilidad psicológica de un "amor" en la Evolución! (p.186).

\section{Referencias}

Arboleda, C. (2003). El ecumenismo en preguntas. Medellín, Colombia: Universidad Pontificia Bolivariana. Secretariado de Ecumenismo de la Arquidiócesis de Medellín.

De Chardin, T. (1967). Nuevas cartas de viaje. Madrid, España: Taurus.

Ferguson, M. (1994). La conspiración de Acuario. Transformaciones y sociales en este fin de siglo. Madrid, España: Kairós.

Huntington, S. P. (2001). El choque de civilizaciones y la reconfiguración del orden mundial. Buenos AiresBarcelona-México: Paidós.

Küng, H. (1992). Proyecto de una ética mundial. Madrid, España: Trotta.

Macionis, J. y Plummer, K. (1999). Sociología. Madrid, España: Prentice Hall.

Marcuse, H. (1969). El hombre unidimensional. Barcelona, España: Seix Barral.

Ramírez, A. (1999). El reto actual de la apertura toca también a la Iglesia y a la Teología. Consideraciones en torno al futuro de la vocación profética de la Iglesia y de la teología en América Latina. Cuestiones Teológicas, 26, 123-143

Ramírez, A. (2000). Consideraciones teológicas acerca del misterio de Dios. Cuestiones Teológicas, 27, 81-115

Ramírez, A. (2003). A los 40 años de la inauguración del Concilio Vaticano II. Cuestiones Teológicas, $30,29-55$

Ramírez, A., Vargas, C. y González, J. . (2011). Hacia un futuro de grandes encuentros. Razones para fundamentar la esperanza. Medellín, Colombia: Universidad Pontificia Bolivariana.

Spengler, O. (1966). La decadencia de Occidente. Bosquejo de una morfología de la historia universal, I. Madrid, España: Espasa-Calpe. 